\title{
Volunteer's Willingness to Genetic Testing - Lack of the Understanding of the Matter
}

\author{
V. ADÁMKOVÁ ${ }^{1,2}$, M. VELEMINSKÝ ${ }^{1}$, P. ZIMMELOVÁ ${ }^{1}$, J. A. HUBÁČEK ${ }^{1,2,3}$ \\ ${ }^{1}$ South Bohemia University, Faculty of Public Health and Social Studies, České Budějovice, \\ ${ }^{2}$ Institute for Clinical and Experimental Medicine, Prague, ${ }^{3}$ Centre for Cardiovascular Research, \\ Prague, Czech Republic
}

Received June 18, 2009

Accepted July 14, 2009

\begin{abstract}
Summary
Medical genetic research achieved in last decade many efforts leading to better understanding of inherited basis of human diseases. This will not be possible without the participation of patients and controls. However, the general understanding of the background and possibilities of genetic association studies is very low. It was confirmed by study of university of students. Because of the fair of misuses of the individual genetic information, significant part of participants refused the use of already donated blood samples for genetic testing but agreed with using of buccal swabs for the same analysis. To enhance the general knowledge's of the population, leading to realistic expectations not just about genetic predictive power but also about the eventual risks in behind will be the major mission in the next years.
\end{abstract}

\section{Key words}

DNA • Knowledge's • Testing • Prediction

\section{Corresponding author}

V. Adámková, IKEM-PPK, Videňská 1958/9, 14021 Prague 4, Czech Republic. Fax: +420261710666. E-mail: vead@ikem.cz

The central object of human genetics is to understand the inherited basis of human diseases and exact role of DNA variation in phenotypic manifestation. The sequencing of the human genome, analysis of gene expression and using of the genome wide association studies were undoubtedly between the major scientific efforts of the last decade and have already had an enormous impact on medicine. It is already possible to point on some important variants of different genes, which have a comparable negative effect on disease development, like for example smoking, obesity, dyslipidemia or hypertension (but, also these factors have an significant genetic component which is estimated to be between 30-80\%) (Terán-García and Bouchard 2007). Recently, we stand very close to the integration of individual genetic and genomic information into personalized health care and maintenance to substantially improve health (at both individual and at population level), increase efficiency, and decrease costs of treatment.

Soon, we will be able not just to integrate information on inherited susceptibility to programs of prevention of major diseases (like for example cancer, cardiovascular diseases, diabetes, or obesity), but probably more importantly, the predicted pharmacogenomic response will refine our medical management in order to lower the costs and enhance the effectivity of the treatment (Boissel et al. 2003).

Molecular genetic tests are, and will be in the near future, available for wide public, also because of the lowering of the cost of testing. However, despite the efforts done in last years, we need to accentuate that so far are our understanding of the genetic predispositions on beginning. Commercially available tests have very low predictive power and the general awareness of the possibilities of medical genetics and genetics overall, are disappointing.

Generally, the vast majority of the population is not able to understand the information given and newspapers are full of mistakes and incomplete information. 
The flashiest examples are around the knowledge's about the genetically modified food. Couple of years ago, more than one third of the European population did believe that genes are not present in common tomatoes, but in genetically modified tomatoes yes and more than half of examined population agreed with the statement that "by eating genetically modified fruit the person's genes could be also become modified" (www.biotrin.cz/eupages/BSBA\%20short.pdf). Quite recently, in Austria is running official anti-GMO campaign speaking about gene-free maize.

This general ignorance is the cornerstone of the fact that general willingness to participation in genetic association study vary between 20-90\% (Sterling et al. 2006, Stewart-Knox et al. 2009).

In Czech Republic, we have performed in last three years large screening concerning the less commonly analyzed risk factors of obesity (among them also genetic tests are planned).

Between analyzed individuals - volunteers, also South Bohemia university students were included $(\mathrm{n}=$ 2105). All have no problems to give some personal data like smoking status, alcohol consumption, birth weight and body weight etc., whose reflect the environmental predisposition to the major diseases mentioned above.

Surprisingly, many of them $(\mathrm{n}=596 ; 28.2 \%)$ refused to sign informed consent with DNA isolation and genetic testing from the blood samples, despite the fact, that these samples were already donated for basic biochemical analysis. As a reason often because of the fear from misuse the genetic information and some individuals even express the fear of "to be cloned". Quite interestingly, almost all ( $\mathrm{n}=583 ; 98 \%$ ) of these individuals, however, gave the informed consent with the analysis of genetic information from the buccal cells, as; it is "something else". They completely misunderstood the fact that the obtained genetic material is virtually the same regardless of the kind of nucleated cells used for the DNA isolation and could be used in the same way. Thankfully, there is no evidence, that response characteristics would in some way be associated with genotype frequencies (Bhatti et al. 2005).

It underlines, that even between the individuals with higher education, the general awareness about genetic generally and genetic testing background and possibilities is very low.

It is not a question if, but when genetics will be definitely utilized in every field of medicine; however, it will be crucial, but much more complicated, to enhance the general knowledge's of the population, leads to realistic expectations not just about its predictive power but also about the eventual risks (which are expected to be very low) in behind.

\section{Conflict of Interest}

There is no conflict of interest.

\section{Acknowledgements}

The study was supported by the project No 8895-4, Ministry of Health, Czech Republic. Authors thank to the participating volunteers.

\section{References}

BHATTI P, SIGURDSON AJ, WANG SS, CHEN J, ROTHMAN N, HARTGE P, BERGEN AW, LANDI MT: Genetic variation and willingness to participate in epidemiologic research: data from three studies. Cancer Epidemiol Biomarkers Prev 14: 2449-2453, 2005.

BOISSEL JP, GUEZFFIER F, CUCHERAT M, BRICCA G: Pharmacogenetics and responders to a therapy: theoretical background and practical problems. Clin Chem Lab Med 41: 564-572, 2003.

MESCHIA JF, MERINO JD: Willingness of ischemic stroke patients to donate DNA for genetic research: a systematic review. J Stroke Cerebrovac Dis 12: 228-231, 2003.

STERLING R, HENDERSON GE, CORBIE-SMITH G: Public willingness to participate in and public opinions about genetic variation research: a review of the literature. Am J Public Health 96: 1971-1978, 2006.

STEWART-KNOX BJ, BUNTING BP, GILPIN S, PARR HJ, PINHAO S, STRAIN JJ, DE ALMEIDA MD, GIBNEY $\mathrm{M}$ : Attitudes toward genetic testing and personalised nutrition in a representative sample of European consumers. Br J Nutr 101: 982-989, 2009.

TERÁN-GARCÍA M, BOUCHARD C: Genetics of metabolic syndrome. Appl Physiol Nutr Metab 32: 89-114, 2007. 